\title{
Design of Longitudinal Motion Controller of a Small Unmanned Aerial Vehicle
}

\author{
Ahmed Elsayed \\ Shoubra Faculty of Engineering, Benha University, Egypt \\ E-mail: eng_medoelbanna@yahoo.com. \\ Ashraf Hafez \\ Shoubra Faculty of Engineering, Benha University, Egypt \\ E-mail: ashrafhafez@hotmail.com. \\ A. N. Ouda \\ Military technical college, Cairo, Egypt \\ E-mail:ahnasroda@yahoo.com \\ Hossam Eldin Hussein Ahmed \\ Faculty of Electronic Engineering, Menufiya University, Menouf, Egypt \\ E-mail: hhossamkh@yahoo.com. \\ Hala Mohamed Abd-Elkader \\ Shoubra Faculty of Engineering, Benha University, Egypt \\ E-mail: hala_mansour56@yahoo.com.
}

\begin{abstract}
The need for autonomous Unmanned Aerial Vehicles (UAVs) is very interesting nowadays. Autonomous UAVs provide the possibility of performing tasks and missions that are currently hazardous or can cost humans or money, enable autonomous search, persistent combat intelligence, surveillance and reconnaissance (ISR), and many other applications. This paper presents an overview of autopilot design with a detailed design of longitudinal autopilot of a Small Unmanned Aerial Vehicle (SUAV). The designed autopilot is applied to an Ultrastick-25e fixed wing UAV depending on longitudinal linear model and analytic linear model with trimmed values of straight and leveling scenario. The longitudinal motion controller design is started with the design of most inner loop (pitch rate feedback) of the longitudinal system, then pitch tracker design with a Proportional Integral (PI)- controller. The guidance and control system is related with the design of altitude hold controller with Pcontroller as an example of outer loop controller design. The performance of two classic controller approaches for the design of autopilot are compared and evaluated for both linear and non-linear models. The proposed controller is chosen for design due to its higher performance than the classic one. At last the climbing turn scenario is applied to the whole autopilot (longitudinal and lateral) for the evaluation process. The results show a good performance in both disturbance rejection and robustness against sensors noise.
\end{abstract}

Index Terms - Nonlinear equations of motion, longitudinal motion controller, pitch tracker, altitude hold controller, sensors noise, environment effects.

\section{INTRODUCTION}

The increased interest in remote sensing applications and the advances in technology attract the researchers of aerospace engineering to design low cost satellites [1] and UAVs [2] for remote sensing and many other applications.

The increased interest in UAVs has resulted in a rapidly growing number of organizations, both military and civilian, and conducting researches to develop fully autonomous UAVs. SUAVs are of particular interest to many researchers around the scientific society, as they are relatively inexpensive, offer the ability to address a multitude of autonomous flight research applications that once seemed out of reach. Using autonomous UAVs of all sizes, and the visions of using them for almost any task leads the way for a more lethal and efficient force in the field too.

The more autonomous ability of UAV, the more complex its guidance and control system, advanced guidance algorithms development is essential and necessary for meeting new requirements with the increasing area of UAV applications and for defining future UAV concepts and associated critical technologies. SUAV control and stabilization is more difficult than larger one, due to several factors, including the low mass of the vehicle, lower Reynolds numbers, and light wing loading. These factors make it more difficult to design a flight control system [3]. 
The complete state of the UAV comprises its position, airspeed $\left(V_{a}\right)$, attitudes (roll $(\phi)$, pitch $\left.(\theta), y a w(\psi)\right)$, angle-of-attack $(\alpha)$, sideslip angle $(\beta)$, and rotation (roll $(p)$, pitch $(q)$, and yaw $(r))$ rates. Position, airspeed, and heading attitude are also known as the navigation states [4]. Control on these states provides full control on the vehicle movements with six degrees of freedom. The requirements of control are to ensure that the dynamics are "fast") and to ensure that the oscillations die out quickly, and also the requirements on a good tracking of command input with minimum steady state errors. Since the open-loop dynamics of the vehicle rarely satisfy these requirements, so the typical approach is to use linear and non-linear feedback control to modify the pole locations and loop gains $[5,6]$.

MATLAB is one of the most important programs used in modeling and controller design of aircraft on which it is possible to simulate and test the performance of an accurate autopilot with linear model, Software In Loop (SIL), and Hardware In Loop (HIL). Root Locus technique and Conventional PI (Proportional Integral) and PID (Proportional Integral Derivative) controllers can be used to design the autopilot and hence to improve their performance characteristics. With respect to nonlinear control many strategies can be considered in the design as sliding mode controller [7, 8]. By converting Multi Input Multi Output (MIMO) linear model of aircraft into a Single Input Single Output (SISO) transfer functions which can be controlled by appropriate P (proportional), PI or PID controllers [9, 10, and 11], a desired Pole- Zero locations affect the stability of the system by a varied gain which can be observed by root locus plot. Gain Margin and Phase Margin can also be determined for a relative stability analysis of the system.

For SUAVs, the autopilot is in complete control of the aircraft during all phases of flight. From beginning, the autopilot is designed according to many philosophies; one of them is the design with two separate design autopilots; longitudinal and lateral motion controller [12], the longitudinal dynamics (forward speed, pitching, and climbing/descending motions) and the lateral dynamics (rolling, and yawing motions) [13]. This design concept simplifies the development of the autopilot and at the same time is accurate.

This paper presents a design of a longitudinal motion controller of SUAV (longitudinal autopilot). Longitudinal Subsystem can be represented by various transfer functions of UAV. Unit-step, doublet response, noise effect, and ability to disturbance rejection tests are executed to check the performance and robustness of autopilot in linear and non-linear models $[14,15]$.

The longitudinal linearized model of ultrastick-25e [13] (state space linearized model) was used in the design of autopilot with the trimming values of a straight and leveling scenario. The behavior of the aircraft due to the desired scenarios results were compared between (the state space linearized and the derived short period analytical linearized models) and the nonlinear aircraft dynamics, the results is too matched between all of the three.

The outer-loops were designed to achieve the tracking command requirements in (altitude, and cruise speed). The inner loops are designed to track pitch attitude reference signals required for the outer loops. Several design goals were introduced against the inner loop performance that the closed loop rise time should be less than 1 second, and the overshoot has to be smaller than 5\% in outer loop but in pitch attitude is in between $7 \%$ to increase the response and decrease the settling time.

Proportional-Integral blocks for the inner loop controller (Pitch Tracker), while for attitude rates a nonunity feedback was introduced (pitch damper). For outer loops controllers a proportional gain was chosen for altitude controller, and for a cruise speed controller PIcontroller was used.

If the controller causes overshoot and degrades the controller performance when coming out of saturation. In order to prevent this, an anti-windup scheme is implemented which checks if the actuator would saturate on the current time step and does not perform the integration if this case is happened [16].

The throttle commands go directly to the aircraft model without any modification by the inner loop. Pitch angle $(\theta)$ has to remain between $20^{\circ}$. Throttle command is limited between the range of 0 and 1 .

Elevator and throttle is the inputs for longitudinal motion controller. Elevator is used to control inner loops (pitch $\theta$, and pitch rate $q$ ) and outer loops height $(h)$, while throttle $\left(\delta_{t}\right)$ is used at the outer loop to control vehicle speed [17].

At last the longitudinal states of aircraft (forward speed $(u)$, vertical speed $(w)$, pitch rate $(q)$, pitch attitude $(\theta)$, altitude $(h))$ are controlled by the control parameters elevator, and throttle $\left(\delta_{e}, \delta_{t}\right)$ respectively.

\section{LONGITUDINAL MOTION CONTROLLER (LONGITUdinal Autopilot) DESIGN PROCEDURES}

The longitudinal autopilot is designed in two stages. First is the pitch tracker (inner loops), second is the

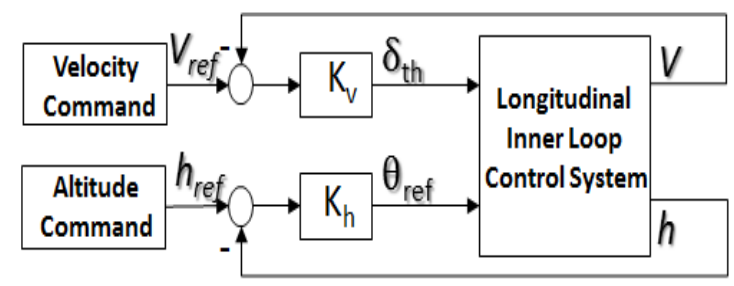

Fig.1. Longitudinal Autopilot Block Diagram

altitude $(h)$ and air speed $\left(V_{a}\right)$ control which is related to guidance and navigation control (outer loops). SUAV altitude hold controller is designed at this assumption the speed is constant (cruise speed) [18]. The performance of the longitudinal motion controller is checked in the scenario of straight and leveling flight, and level climbing flight. The block diagram of longitudinal autopilot 
is shown in Fig. 1

The simulation results of longitudinal autopilot at Figs. (5, 6, 7, 8, 11, 12, 13, 14, 15, and 16) show that the PID classic controller structure outlined in this paper can adequately control the altitude. The cruise speed controller of the aircraft is designed with the same manner to achieve the guidance and navigation requirements.

\section{INNER LOOP PITCH AtTITUde TRACKER DESIGN}

At longitudinal inner loop, the beginning with the most inner loop which is the pitch damper (stability augmentation system (SAS)) [19], this is done to provide satisfactory natural frequency and damping ratio for the short period mode. This mode involves the variable pitch rate, and feedback it to the elevator control as shown in Fig. 2 to provide a good natural frequency and damping with a feedback gain. Pitch rate feedback provides a complete control of position of the short period poles.

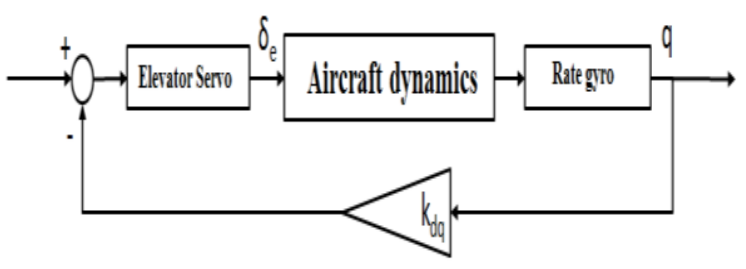

Fig.2. Block diagram of the pitch rate feedback controller.

The linearized transfer function of $\left(q / \delta_{e}\right)$ is fed back and the root locus technique can be applied to determine the effect of the variable $\mathrm{k}_{\mathrm{d}_{-} \mathrm{q}}$. The approximated short period transfer function for pitch rate is shown as in (1) [13]:

$$
\frac{q}{\delta_{e}}=\frac{-133.7 s-990.7}{s^{2}+23.37 s+235.9}
$$

The Eigenvalues are $(-11.7 \pm 9.97 \mathrm{i})$ with damping ratio $\xi=0.761$ and natural frequency $w_{n}=$ $15.4 \mathrm{rad} / \mathrm{sec}$. the value of damping ratio is good but the effect of actuator will get the response slower, so the choice of the gain is to increase the damping [19]. Fig. 3 draws a root loci of the pitch rate inner loop with feedback gain value $\mathrm{k}_{\mathrm{d}_{\mathrm{q}} \mathrm{q}}=-0.065$, which increases the damping; the negative sign shifts the root loci to the left hand side plane. This value is the optimum value after the test of the whole longitudinal motion controller and is chosen to smooth the response trajectory of the pitch tracker. Finally we must note that the feedback gain is negative, this means that an increasing of pitch angle gives the elevator a positive displacement. Alpha feedback is designed at the condition of any pole in the right hand side plane [19], so a desirable short period poles location is achieved for this aircraft with pitch rate feedback only.

The second inner loop is Pitch attitude hold controller, called pitch tracker because its main task is to maintain the value of pitch attitude $(\theta)$ matched with the commanded pitch. Equation (1) can be called again to design pitch attitude tracker, then adding an integrator to obtain pitch from pitch rate for simplicity.

PI controller is used to design pitch tracker. $\mathrm{P}$ controller alone is not sufficient for the stability due to some steady state error (constant disturbance), so it can

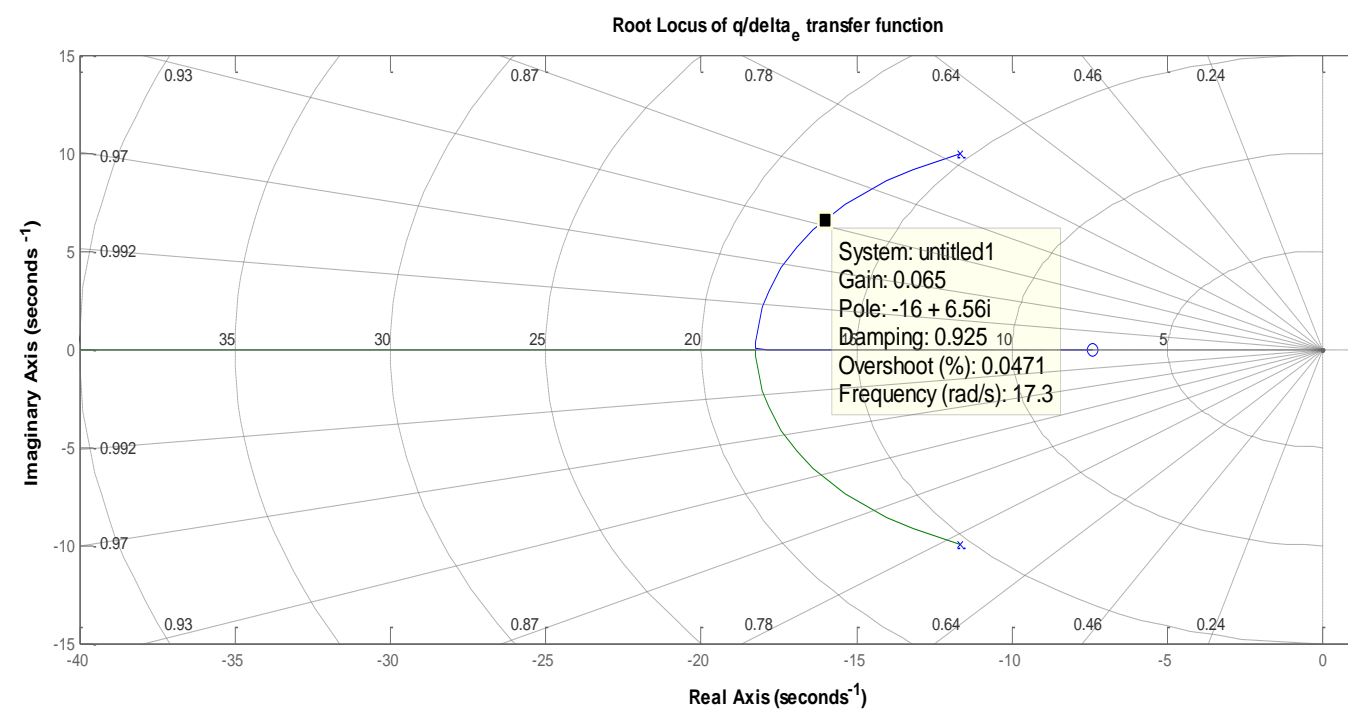

Fig.3. Most inner loop root locus of pitch tracker 


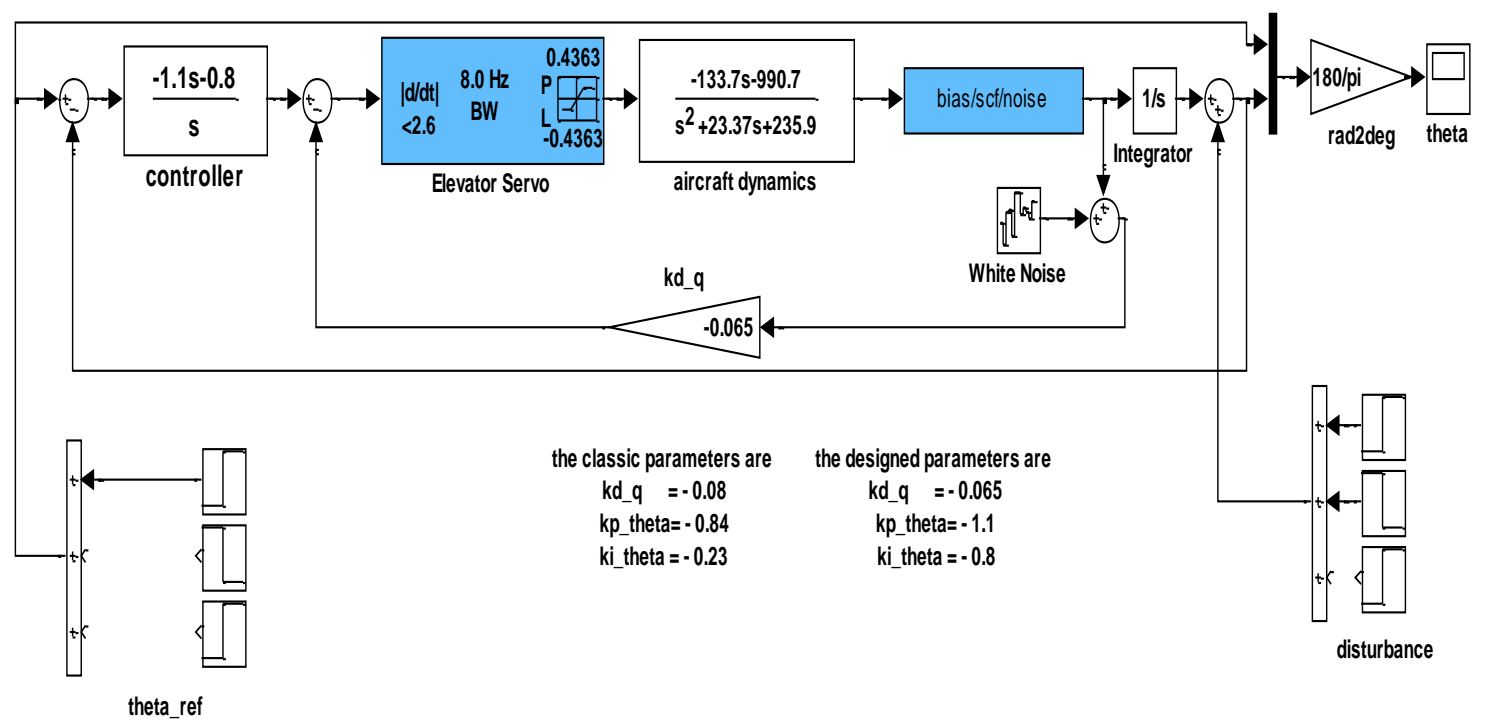

Fig.4. Simulink MATLAB structure of pitch attitude hold controller.

be eliminated by adding integrator, so PI controller is used.

The Simulink MATLAB structure for pitch tracker is seen in Fig. 4, the values of $k_{p} \theta, k_{i \theta}$ gains depending on the concept of Ziegler [9] were obtained as initial values, and then by some iteration with the aiding of Simulink test platform; the exact values of gains were chosen to make a good pitch tracking. The designed new parameters assured that the performance of the designed pitch attitude tracker is better than the classic one as in the simulated program of the research group of Minnesota University [20].

The classic parameters are $\left(\mathrm{K}_{\mathrm{d}_{-} \mathrm{q}}=-0.08, \mathrm{k}_{\mathrm{p}_{-} \theta}=-\right.$ 0.84 , and $\left.\mathrm{k}_{\mathrm{i} \theta}=-0.23\right)$, and the designed parameters are $\left(\mathrm{K}_{\mathrm{d} \_\mathrm{q}}=-0.06, \mathrm{k}_{\mathrm{p} \theta}=-1.1\right.$, and $\left.\mathrm{k}_{\mathrm{i} \theta}=-0.8\right)$. The executed tests on the two controllers are in the next section.

\section{INNER LOOPS OF LONGITUDINAL MOTION CONTROLLER TEST RESUltS}

This section introduces list of analysis tests beginning with:

A. Time Domain Analysis from Unit Step Response.

Table 1. Time domain analysis of pitch tracker

\begin{tabular}{|c|c|c|}
\hline The property & Classic controller & Designed controller \\
\hline $\mathrm{t}_{\mathrm{r}}[\mathrm{sec}]$ & 0.6832 & 0.4333 \\
\hline $\mathrm{t}_{\mathrm{s}}[\mathrm{sec}]$ & 15.3072 & 6.7472 \\
\hline Settling min. & 0.9004 & 0.9011 \\
\hline Settling max. & 0.9993 & 1.0673 \\
\hline Max. O.S. \% & 0 & 6.7287 \\
\hline Undershoot\% & 0 & 0 \\
\hline Peak & 0.9993 & 1.0673 \\
\hline Peak time $[\mathrm{sec}]$ & 35.7583 & 1.1312 \\
\hline
\end{tabular}

By applying unit step response test the following parameters can be tested and the results as in table 1 .

From table 1 the designed controller from the standalone model in fig. 4 the rise time and setting time and the other specs are better than the classic one, but maximum overshoot is designed to be more than normal to make the system multi steps of attitudes as in fig. 8. The remaining factors evaluate Pitch tracker are doublet signal response, the effect of the micro-electromechanical systems (MEMS) noisy sensors, and ability of the system to reject the disturbance.

\section{B. Doublet Signal Response.}

The angle $\theta$ _ref five degree Doublet signal of pitch angle was applied and watches the signal response in linear Simulink.; the responses of the pitch tracker for two controllers are shown in Fig. 5 which investigate that the maximum over shoot of the designed parameters is larger than the classic, but this property has a good benefit, this benefit is showed in the multistep desired angles response in Fig. 8.

\section{The Effect of Noisy Sensors with Standard Deviation $\boldsymbol{\sigma}=0.001 \mathrm{Rad}$.}

The availability of using new sensor technologies gives the designers the availability to design SUAV sensors depending on MEMS. These sensors are smaller and lighter than the old mechanical sensor devices. It provides the possibility to shrink the size and weight of the UAV to a new milestone. MEMS are low cost, but so noisy. 


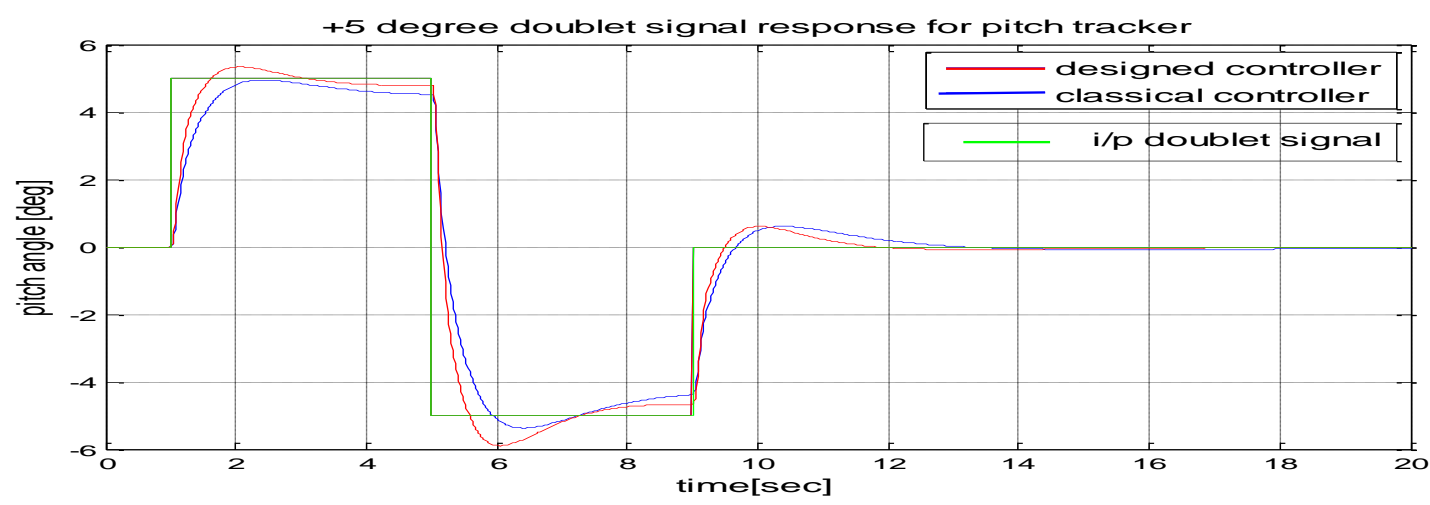

Fig.5. +5 degree doublet signal response for pitch tracker.

The solution for beating the noise and obtain a precise results for attitudes and navigation states is to design a good robust controller with good analysis and using state estimator depends on a good estimators. KALMAN filter is one of the best estimators; it's involved with most of GPS-INS techniques [21, 22]. In this paper we will discuss the control performance against noisy sensors with no details in the state estimator which will be in the future work of designing the whole autopilot at another work in details. Fig. 6 illustrates the trajectory of the response in the effect of noise with standard deviation till $(0.001 \mathrm{rad})$. The assumption that the bias of the sensors will be eliminated is considered. As seen from the Fig. 6 that the two controllers are acceptable, with KALMAN filter state estimator technique these noises will be eliminated.

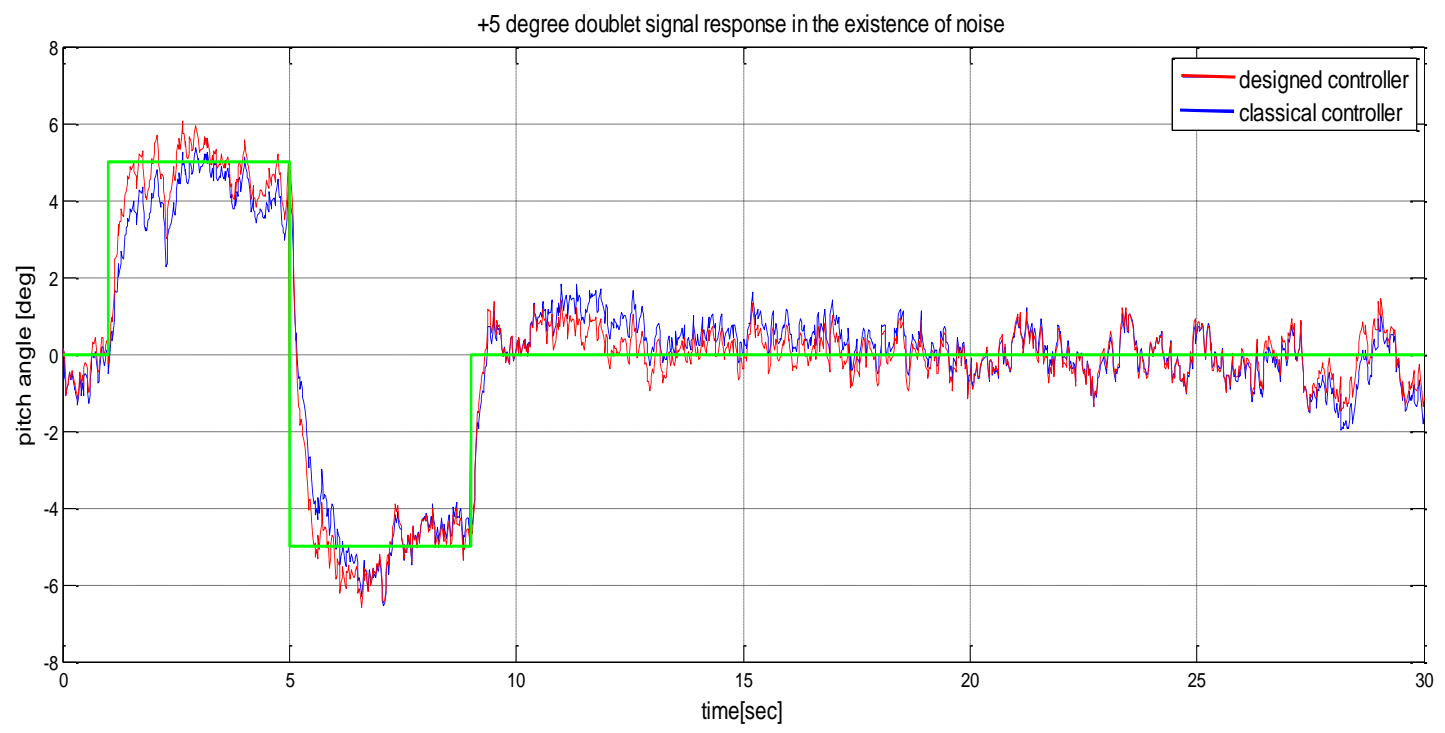

Fig.6. The effect of sensors noise in the doublet signal response.

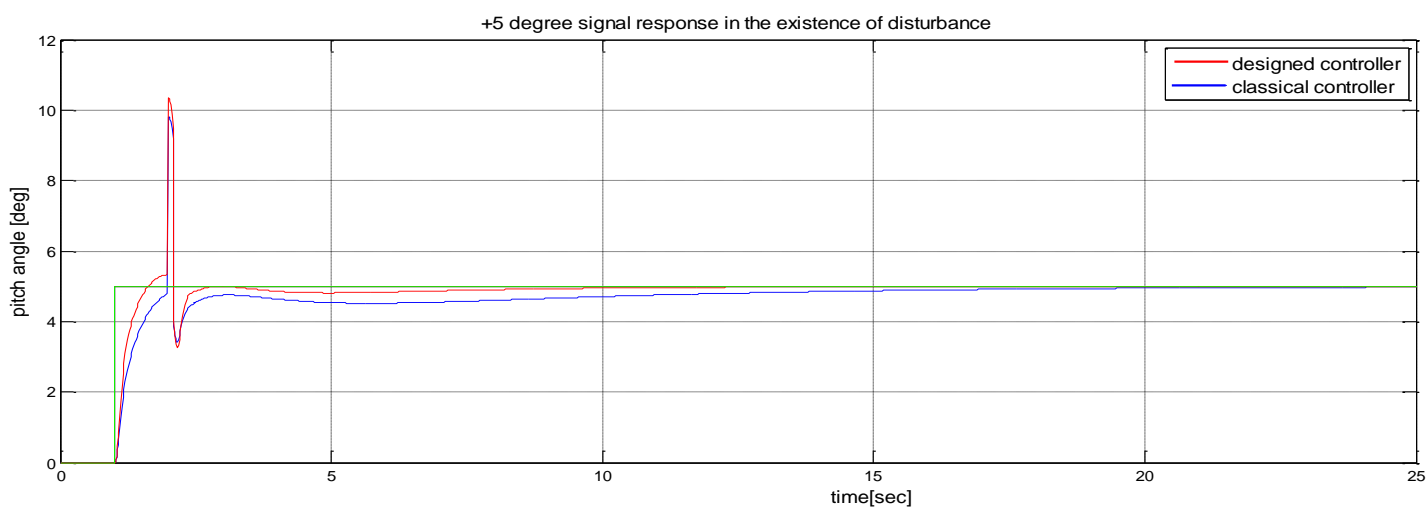

Fig.7. The ability of pitch tracker to disturbance rejection. 
to environments or any other disturbance, Fig. 7 shows the ability of the two controllers to reject the disturbance which assures that the designed controller rejects the disturbance faster than the classic one.
Increasing the maximum overshoot of the response in the step response aided the designed controller to track the desired inputs of pitch attitude, but in the classic controller the errors are accumulated to result a poor track in the multi steps test as seen in the Fig. 8.

\section{E. Multi Steps Response.}

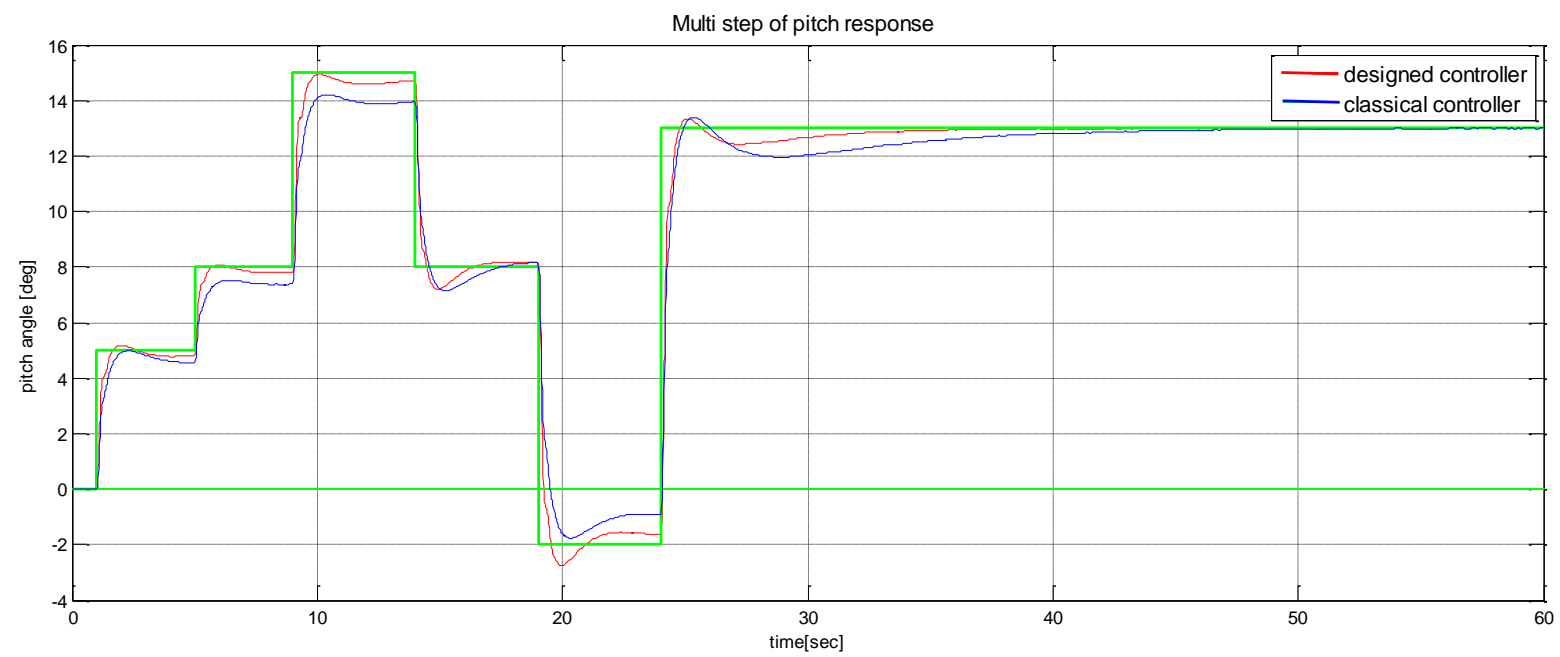

Fig.8. Multi commanded steps of pitch attitude response.

Briefly, the previous sections introduced the philosophy of designing of pitch tracker with PID controller and evaluation of the design. The next section introduces the design procedures of outer loop altitude hold controller.

\section{OUter LoOp Altitude Hold CONTROLler DESIGN}

From the non-linearized equations of motion [13], a linear relation between altitude and pitch attitude at a constant airspeed is derived. From (2) it can be linearized with some assumptions compatible with longitudinal motions.

$$
\dot{h}=u \sin \theta-v \sin \phi \cos \theta-w \cos \phi \cos \theta
$$

With this equation, it can be seen that the pitch angle can directly influence the climbing rate of the aircraft, but at constant airspeed (cruise speed). The linearized equation can be derived by the following steps,

First: from (2) add and subtract the term $\left(V_{a} \theta\right)$.

$$
\begin{gathered}
\dot{h}=V_{a} \theta+\left(u \sin \theta-V_{a} \theta\right)-v \sin \phi \cos \theta \\
\quad-w \cos \phi \cos \theta \\
\Rightarrow \dot{h}=V_{a} \theta+d h
\end{gathered}
$$

Where:

$d h=\left(u \sin \theta-V_{a} \theta\right)-v \sin \phi \cos \theta-w \cos \phi \cos \theta$

Second: In straight and level flight condition, where $v \approx 0, w \approx 0, u \approx V_{a}, \phi \approx 0$, and $\theta$ is small [18], so we have $d h \approx 0$.

Third: if airspeed is constant, by converting (3) into the Laplace domain, the linearized transfer function of the altitude from pitch attitude is as follows:

$$
h(s)=\frac{v_{a}}{s}\left(\theta+\frac{1}{v_{a}} d h\right)
$$

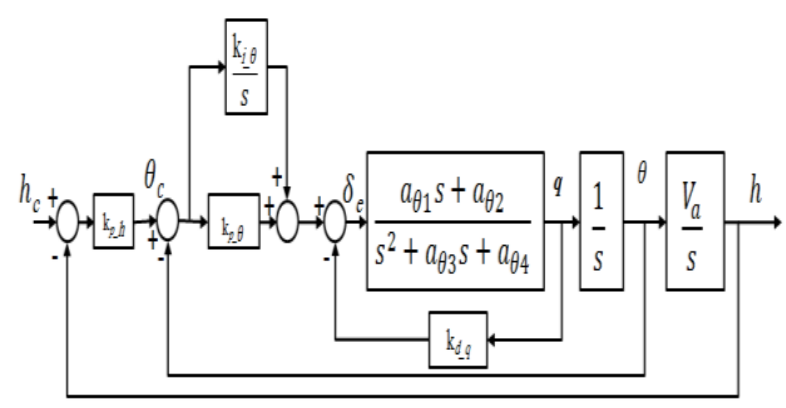

Fig.9. Block diagram of the designed altitude hold controller.

The block diagram of altitude hold controller is shown in Fig. 9; it's constructed from pitch depending on (4).

So MATLAB structure block diagram as in Fig. 10 with the model of sensors noise, disturbances, and model of first order servo motor as an actuator. Executed tests showed that the designed controller is better than the classic one as seen in Figs. (11, 12, 13, 14, 15, and 16). The classic control parameters are $\left(\mathrm{K}_{\mathrm{d}_{-} \mathrm{q}}=\right.$ $0.08, \mathrm{k}_{\mathrm{p}_{-} \theta}=-0.84, \mathrm{k}_{\mathrm{i}_{-} \theta}=-0.23, \mathrm{k}_{\mathrm{p}_{-} \mathrm{h}}=0.021$, and 
$\left.\mathrm{k}_{\mathrm{i} \_\mathrm{h}}=0.0017\right)$, and the designed one $\left(\mathrm{K}_{\mathrm{d} \_\mathrm{q}}=-0.06\right.$, $\mathrm{k}_{\mathrm{p}_{-} \theta}=-1.1, \mathrm{k}_{\mathrm{i}_{-} \theta}=-0.8, \mathrm{k}_{\mathrm{p} \_\mathrm{h}}=0.05$, and $\left.\mathrm{k}_{\mathrm{i} \_\mathrm{h}}=0.00\right)$.
The next section represents the result analysis of controller design.

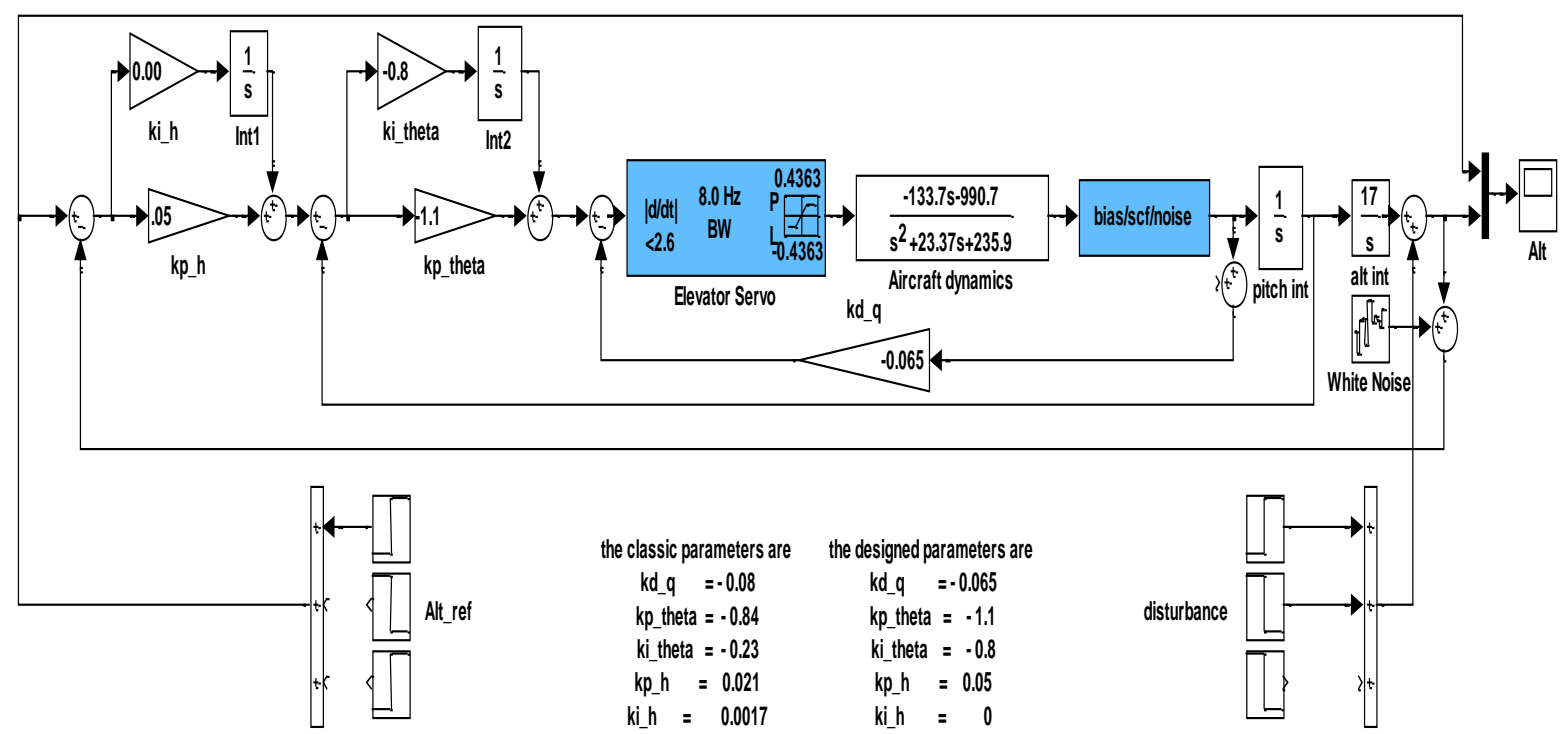

Fig.10. MATLAB Structure of altitude hold controller

\section{LONGITUDINAL MOTION CONTROLLER OUTER LOOP TEST RESULTS}

The evaluation of the longitudinal autopilot is introduced at the following various tests beginning with the time domain analysis

\section{A. Time Domain Analysis.}

Time domain analysis parameters of outer loop are listed in Table 2.
Table 2. Time domain analysis of outer loop of longitudinal motion controller

\begin{tabular}{|c|c|c|}
\hline The property & Classic controller & Designed controller \\
\hline $\mathrm{t}_{\mathrm{r}}[\mathrm{sec}]$ & 4.0431 & 2.1814 \\
\hline $\mathrm{t}_{\mathrm{s}}[\mathrm{sec}]$ & 31.1408 & 4.8717 \\
\hline Settling min. & 0.9070 & 0.9015 \\
\hline Settling max. & 1.1397 & 1.005 \\
\hline Max. O.S. $\%$ & 13.0716 & 0.5006 \\
\hline Undershoot\% & 0 & 0 \\
\hline Peak & 1.1397 & 1.005 \\
\hline Peak time [sec] & 11.5481 & 9.0188 \\
\hline
\end{tabular}

B. Step Response Analysis.

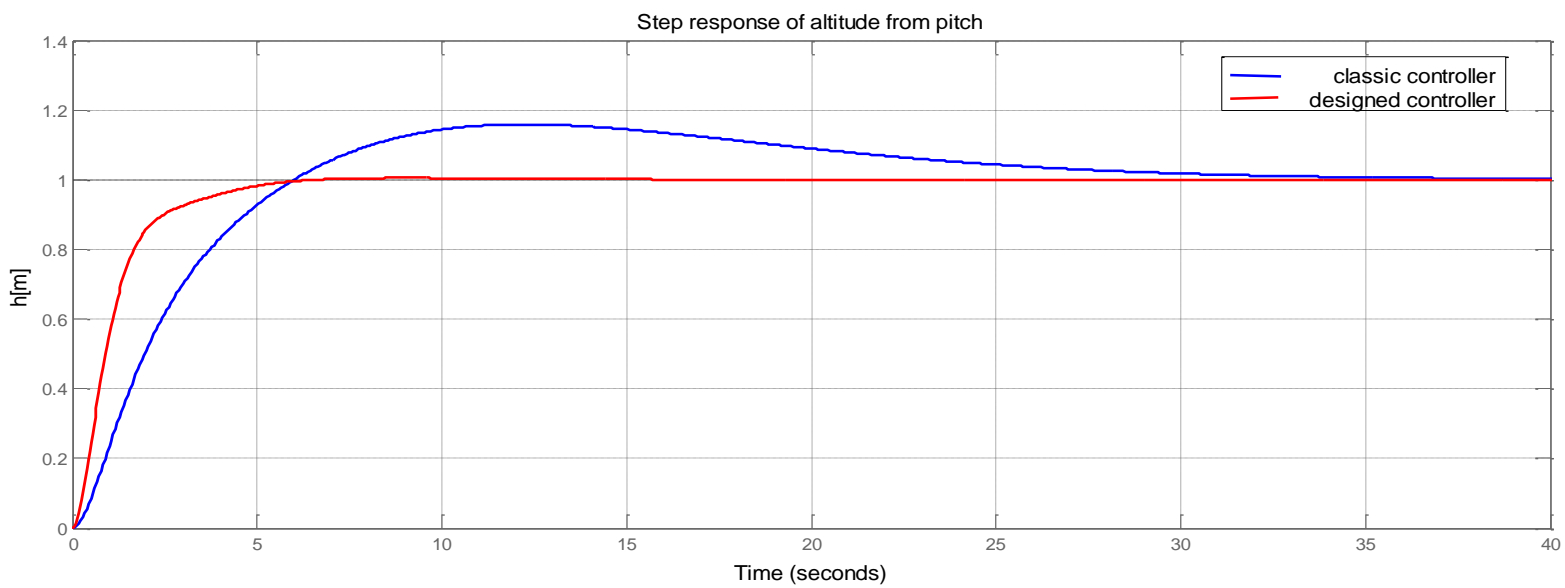

Fig.11. Step response of altitude hold controller.

Step response of altitude hold controller is shown in Fig. 11. The designed controller is better than the classic controller which is obvious in the climbing scenario at Fig. 13.

\section{10 [m] Altitude Doublet Signal Response.}

When $10 \mathrm{~m}$ doublet signal is applied as a desired altitude to the controllers, the outputs of the 


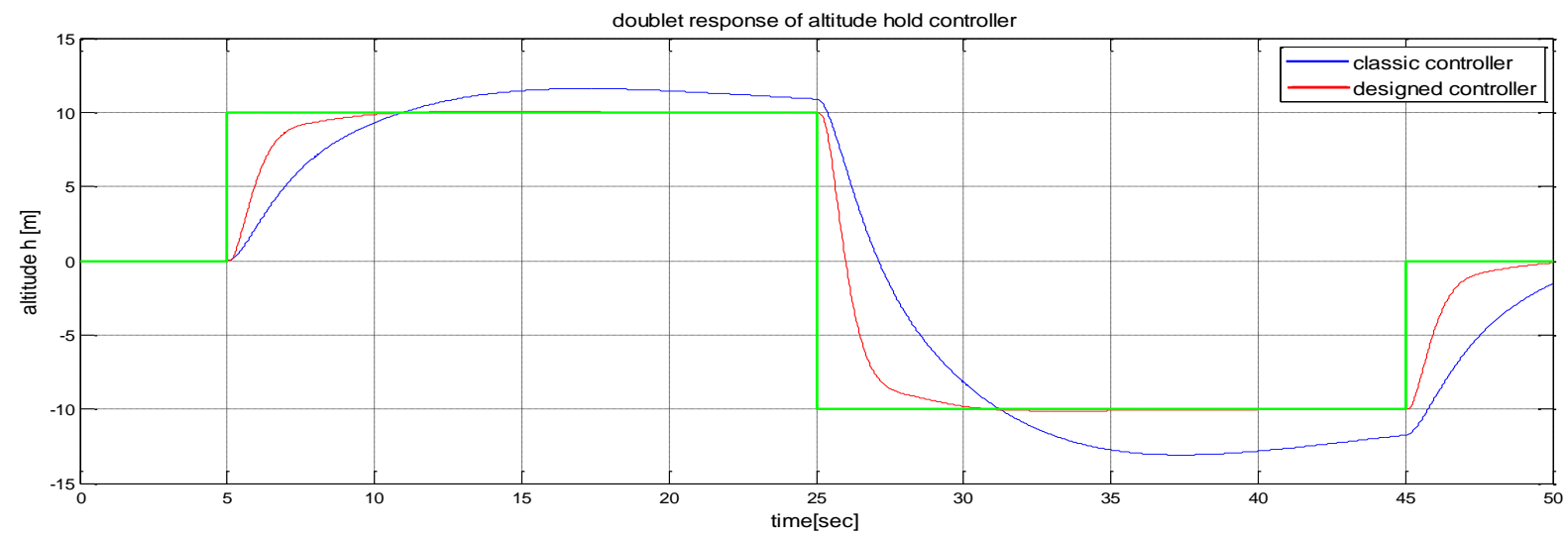

Fig.12. $+10[\mathrm{~m}]$ doublet signal response.

D. The Output Changes against Noise with Standard Deviation $=0.001 \mathrm{~m}$

The effect of sensors noise can be considered as no effect on the altitude hold controller as seen from Fig. 13 with the considering of calibrating the altimeter periodically to prevent it from accumulated errors.

\section{E. Ability of The System To Reject The Disturbance}

The test of disturbance rejection is executed in the step response after very steady state. From Fig. 14 the response is focused at a time from $58 \mathrm{sec}$. to $70 \mathrm{sec}$.

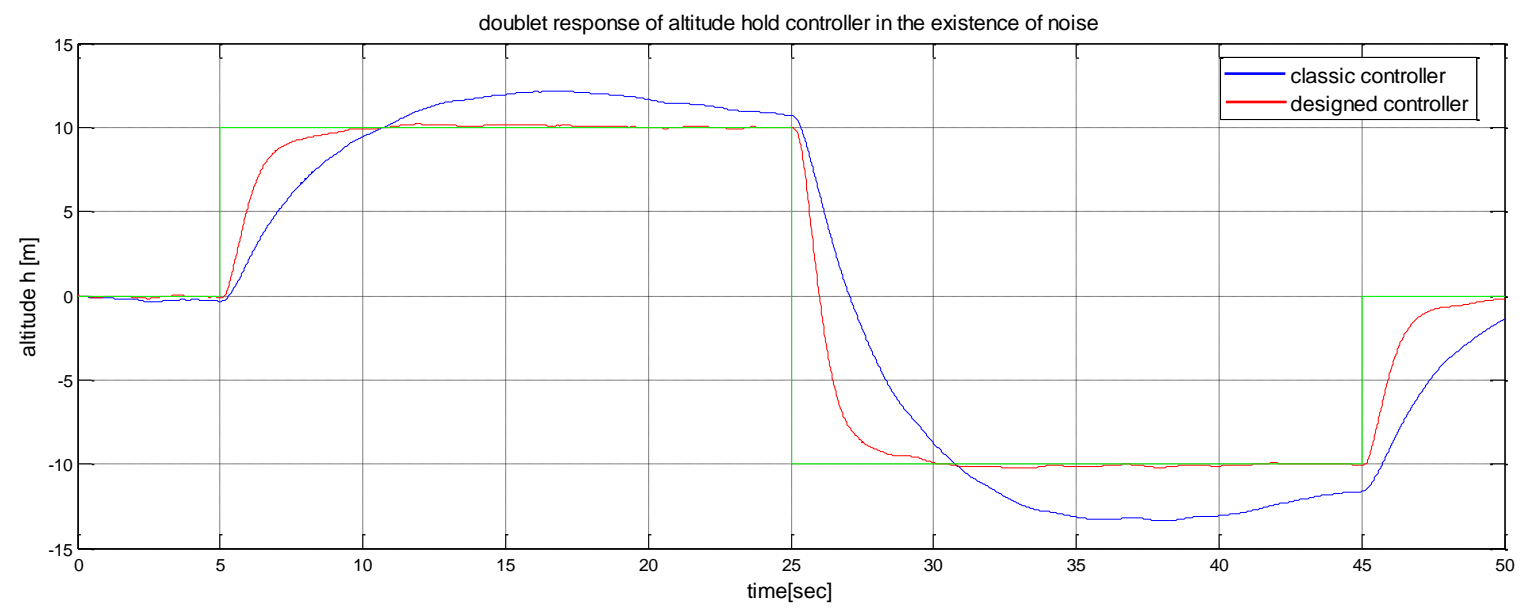

Fig.13. The effect of noise in the altitude hold controller.

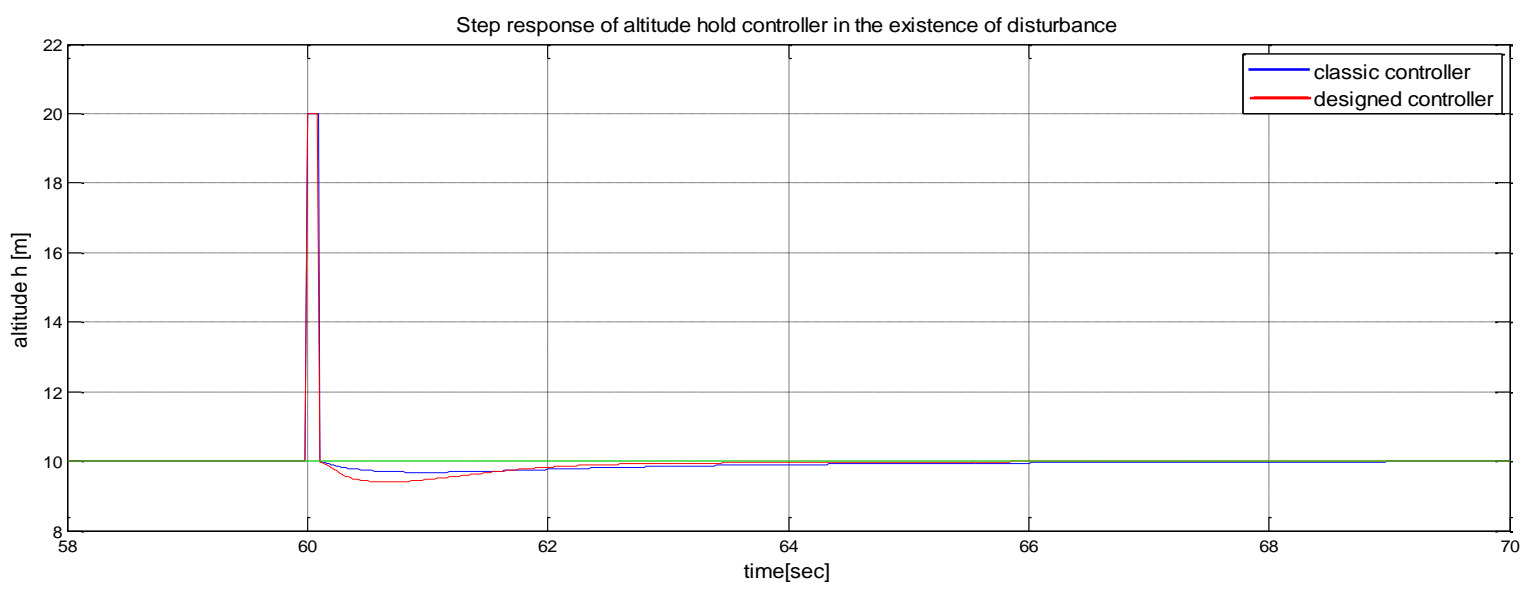

Fig.14. The effect of disturbance on the altitude hold controller. 
By the previous tests, the basic tests of the controller were executed under linear model. The next section is final test results on the autopilot at whole.

\section{Autopilot Tests Results}

This section with the aiding of the previous test sections was done to evaluate the whole longitudinal motion controller and last whole autopilot with longitudinal and lateral motion controllers for non-linear model of aircraft in existence of noisy sensors and environment model [23] at the basic navigation scenarios of the aircraft as straight and leveling, and level climbing.

\section{A. Climbing Level Scenario Test.}

The two controllers are checked in the state space linear model by applying climbing scenario $100[\mathrm{~m}]$ then straight and leveling as in Fig. 15. The test shows that the error in climbing from the designed controller is better than the classic controller.

\section{B. Level Climb (10 M) Comparison}

This test is done between analytical linear model and nonlinear model in the existence of sensors noise and environmental of nonlinear model as shown in Fig. 16.

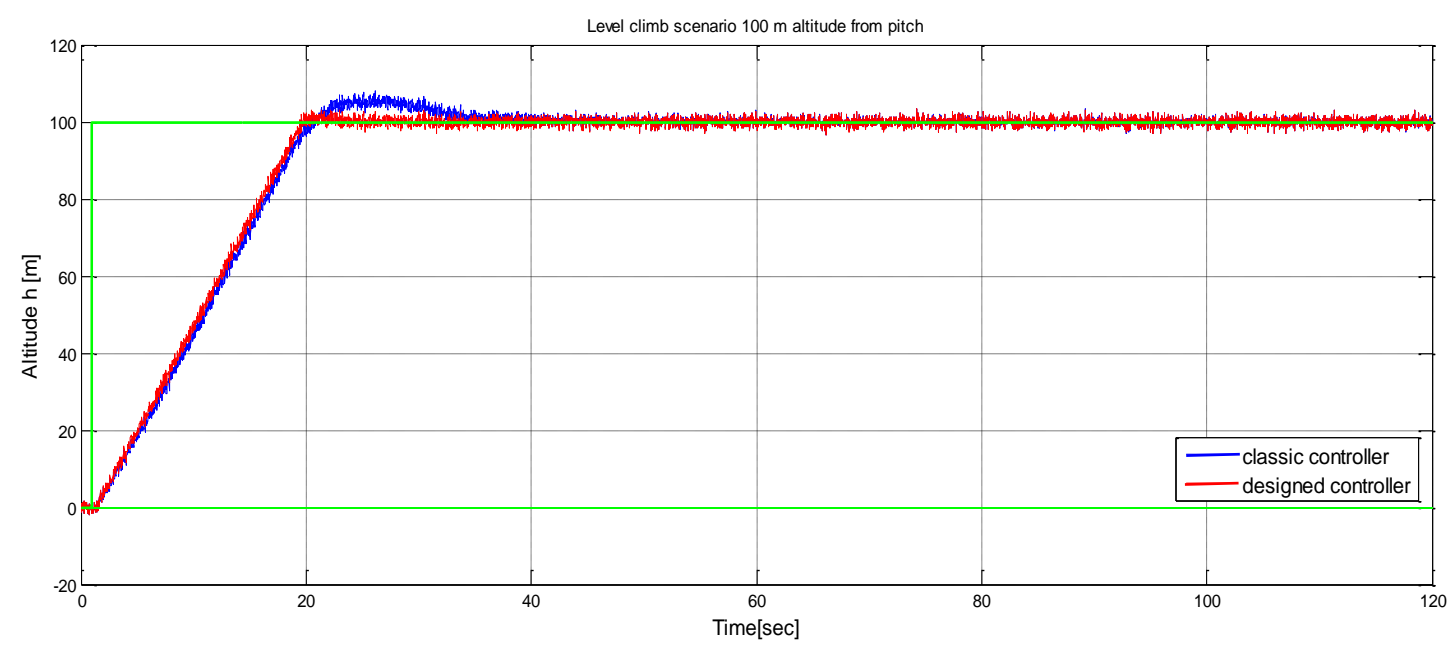

Fig.15. Level Climb 100 meter altitude from the pitch

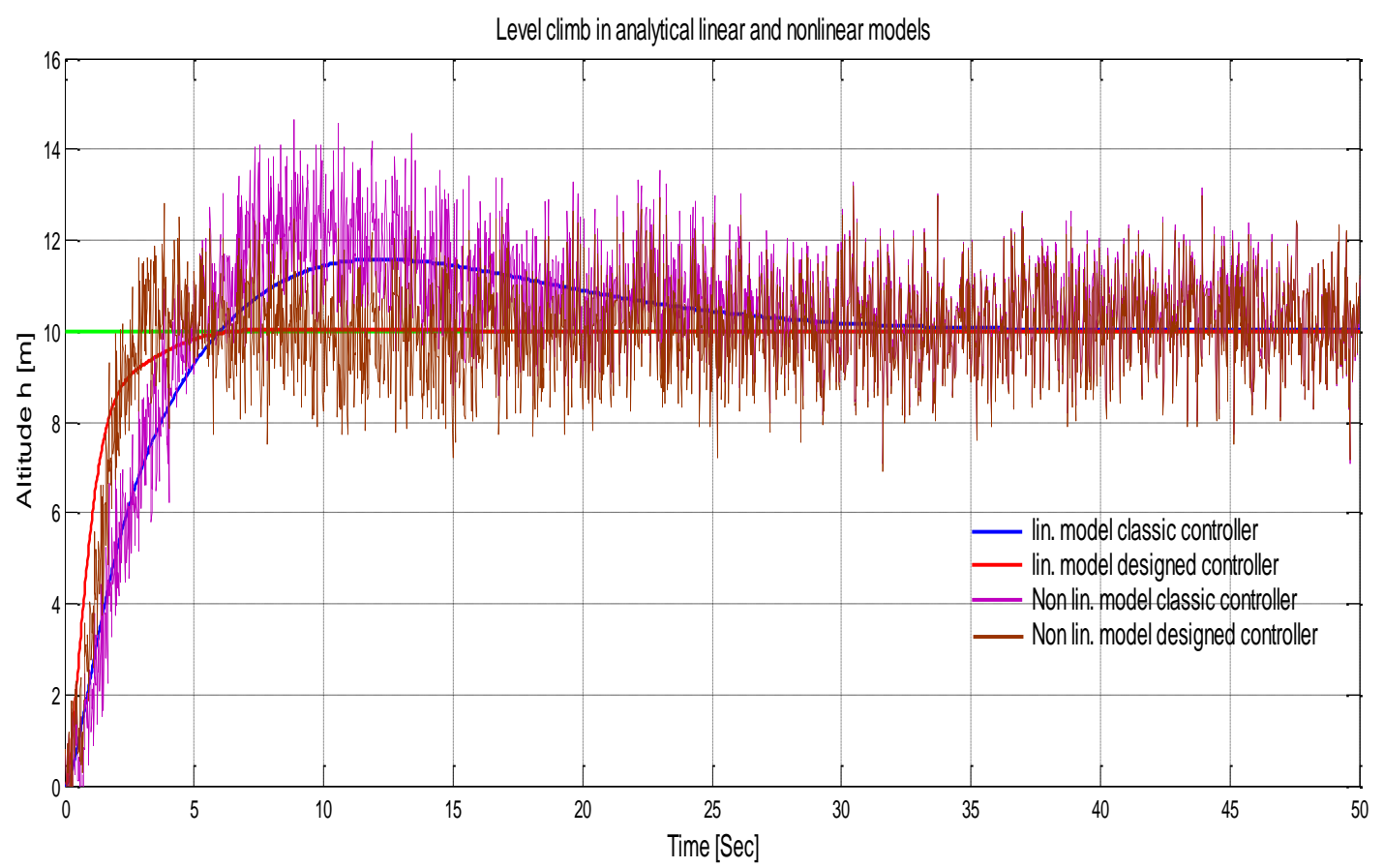

Fig.16. Comparison between the classic and designed controllers applied on the approximated analytical linear model and non-linear model 


\section{Climbing Turn Scenario}

The last test is to evaluate the whole performance of the autopilot (lateral and longitudinal motion controllers) in the Climbing Turn scenario. The altitude command is from 100 to 600 meter and the heading in rectangular motion the response and simulated results is shown in Fig. 17.

- Simulation time $120 \mathrm{~s}$

- Turn in 4 steps heading direction from 0 to 90 and then and then.

- Altitude command $500 \mathrm{~m}$ ascending.

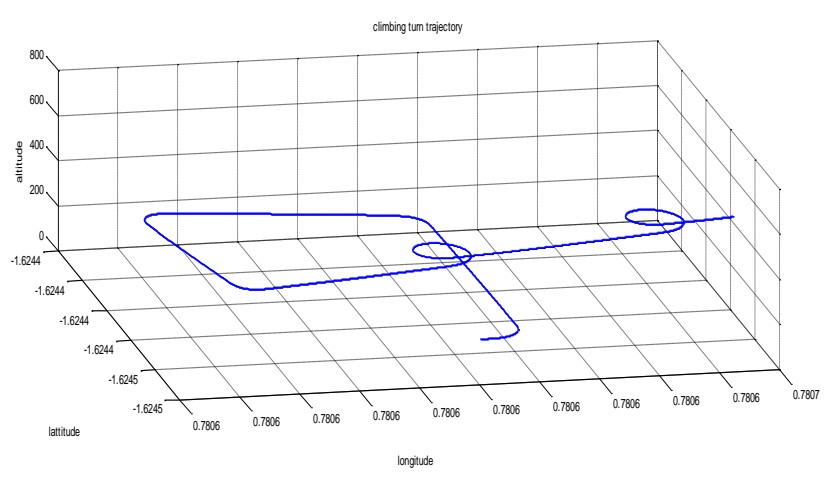

Fig.17. Climbing turn trajectory of the aircraft

\section{CONCLUSION}

In this paper, the design of autopilot is overviewed with the detailed design of longitudinal motion controller. Beginning with the inner loop pitch rate (q) (pitch damper) which is designed with optimum value of feedback gain by root locus technique and tuning it with the nonlinear simulator, and then pitch attitude hold controller (pitch tracker) which is designed with PIcontroller far away from complexity with good performance in the time domain characteristics. Linearization of the nonlinear equation of motion of altitude dynamics is derived to get a linear relation between altitude and pitch angle at assumption of constant air speed (cruise speed of $17 \mathrm{~m} / \mathrm{s}$ ). Altitude hold controller was designed using of P-controller with results are better than PI-controller in the classic controller. Ascending scenario is tested in the non-linear model to check the behavior of the aircraft. The environment disturbances and sensors noise are considered in the design architecture of test platform. The whole autopilot is tested under climbing turn scenario. At the end we can say that we have robust autopilot for autonomous SUAV. GPS-INS system and hardware implementation of the designed autopilot are under development as soon as possible.

\section{ACKNOWLEDGMENT}

The authors would like to thank the anonymous reviewers for their careful reading of this paper and for their helpful comments. This work was supported by Shoubra Faculty of Engineering in Benha University Egypt.

\section{REFERENCES}

[1] Ahmed. H.E.H., Kamal. E., Elsayed. A.," Telemetry Microcomputer Application in Satellites OBC", IEEE, 2009 DOI: 10.1109/AHICI.2009.5340347.

[2] Sridhar Bandaru, Amarjot Singh,"Advanced Mobile Surveillance System for Multiple People Tracking", IJISA, vol.5, no.5, pp.76-84, 2013.DOI: 10.5815/ijisa.2013.05.09

[3] Reed Siefert Christiansen, "Design Of An Autopilot For Small Unmanned Aerial Vehicles” ,Brigham Young University, August 2004.

[4] Gleason, D. Gebre-Egziabher," GNSS Applications and Methods" Artech House, Boston, 2009.

[5] Farid Colnaraghi, Benjamin C.kuo, "Automatic Control Systems, 9th Ed.", John Wiley \& Sons, 2010.

[6] kimono P. Valvanis. George J. Vachtsevanos, "Handbook Of Unmanned Aerial Vehicles", Springer Science, 2015.

[7] Iman Nazari, Ali Hosainpour, Farzin Piltan, Sara Emamzadeh, Mina Mirzaie,"Design Sliding Mode Controller with Parallel Fuzzy Inference System Compensator to Control of Robot Manipulator", IJISA, vol.6, no.4, pp.63-75, 2014. DOI: 10.5815/ijisa.2014.04.07

[8] Sanaz Yadegar, Azura binti Che Soh,"Design Stable Robust Intelligent Nonlinear Controller for 6- DOF Serial Links Robot Manipulator", IJISA, vol.6, no.8, pp.19-38, 2014. DOI: 10.5815/ijisa.2014.08.03

[9] Katsuhiko Ogata, "Modern Control Engineering 5th Ed.", Prentice Hall, 2010.

[10] R. C. Nelson, "Flight Stability And Automatic Control 2nd Ed.", New York. McGraw-Hill. (1998).

[11] D. Tyreus and W. L. Luyben, "Tuning PI Controllers For Integrator/Dead Time Processes", Industrial and Engineering Chemistry Research, vol. 31, no. 11, (1992), pp. 2625-2628.

[12] Stewart, "Calculus: Early Transcendentals, 7th Ed.". Thomson Brooks/Cole, Belmont, 2011.

[13] Elsayed. A, Hafez. A, Ouda. AN, Ahmed H.E.H., AbdElkader H.M, "Modeling of a Small Unmanned Aerial Vehicle", international journal of mechanical, aerospace, industrial and mechatronics engineering $\mathrm{Vol}$ : 9, No: 3 413-421 2015.

[14] MathWorks Inc., Matlab \& Simulink, (2012).

[15] C. Yun and X.-M. Li, "Aerodynamic Model Analysis and Flight Simulation Research of UAV Based on Simulink", Journal of Software Engineering and Applications, vol. 6, (2013), pp. 43-47.

[16] G. F. Franklin, J. D. Powell, and M.Workman, "Digital Control of Dynamic Systems" Pearson Education, 3rd ed., 2005.

[17] M. Chiaramonti and G. Mengali, "Control Laws For A Formation Of Autonomous Flight Vehicles", Aeronautical Journal, vol. 113, no. 1147, (2009), pp. 609-616.

[18] Randal W.Beard, Timothy W.Mclain, "Small Unmanned Aircraft: Theory and Practice", Princeton university press, 2012.

[19] B. L. Stevens and F. L. Lewis, "Aircraft Control and Simulation, 2nd Ed.", Hoboken, NJ: John Wiley \& Sons, Inc., 2003.

[20] Murch, A., Dorobantu, A., and Balas, G., "University 
of Minnesota UAV Flight Control Research Group," http://www.uav.aem.umn.edu, 5 March 2015.

[21] Mohinder S. Grewal, Angus P. Andrews," KALMAN Filtering Theory And Practice Using MATLAB, 4th Ed.", John Wiley \& Sons, January 2015.

[22] Mohinder S. Grewal, Angus P. Andrews, Chris G. Bartone,"Global Navigation Satellite Systems, Inertial Navigation, and Integration, 3rd Ed.", John Wiley \& Sons, 2013.

[23] T. R. BEAL. "Digital Simulation Of Atmospheric Turbulence For Dryden And Von Karman Models", Journal of Guidance, Control, and Dynamics, Vol. 16, No. 1 (1993), pp. 132-138

\section{Authors' Profiles}

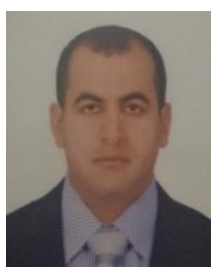

Ahmed Elsayed was born on August 30, 1980. He received the B.Sc. degree from Military Technical College (MTC) in 2002 and M.Sc from Benha University in 2010, Now he is Ph.D Student in Benha University. In 2005, he joined the Benha University, in The Egypt. His representative published articles lists as follow: Telemetry Microcomputer Application in Satellites OBC (IEEE international conference AHICI, 2009), Precise Method of Orbit Height Determination (38th Assembly of the Committee on Space Research (COSPAR) in Bremen 2010), and Modeling of a Small Unmanned Aerial Vehicle (international journal of mechanical, aerospace, industrial and mechatronics engineering Vol: 9, No: 3 2015). His research interests include aerospace engineering, microprocessor architecture, control theory, especially his researches in aerospace engineering and embedded system design.

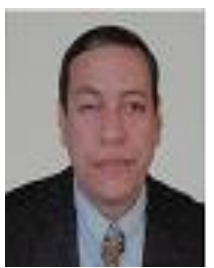

Ashraf M. Hafez was born in Egypt 1959. $\mathrm{He}$ received his B.sc. in electronics and Communication Engineering with honor degree 1981, M.Sc. 1987 and Ph.D. 1992 in Electronics all from Shoubra faculty of Engineering Zagazig University. His Ph.D. thesis was about the design and implementation of the the $1^{\text {st }}$ mobile robot in Egypt. He is currently an assist. Prof. of Electrical Engineering at Shoubra Faculty of Engineering Benha University. His research includes robotics, UAV, control engineering, embedded applications, machine vision, DSP and softComputing.

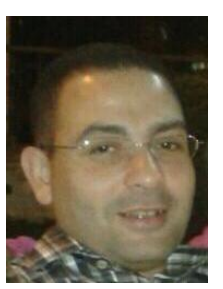

Ahmed N. Ouda was born on February 1, 1977. He received the M.Sc. and PH.D. Degrees from Military Technical College, Egypt, in 2005 and 2012, respectively. In 2012, he joined the Military Technical College, Egypt, as a Teacher. His representative published articles lists as follow, Hybrid Fuzzy-Conventional Controller for Command Line-Of-Sight Guidance System(4th International Conference on Electrical Engineering ICEENG 2004), Robust CLOS Guidance and Control: Part-3: HIL Systems Simulation(14th International Conference on Aerospace Sciences \& Aviation Technology 2011), Design And Analysis of Quad-Copter Classical Control(16th
International Conference on Aerospace Sciences \& Aviation Technology 2015). His research interests include aerospace engineering, classical and advanced control theory, especially his researches in aerospace engineering and embedded system design.

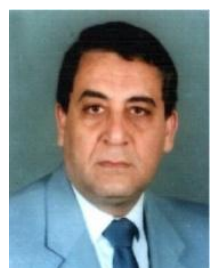

Hossam Eldin H. Ahmed received a BSC (Hons) in Nuclear Engineering in June 1969, An MSc in microelectronic electron diffraction in April 1977 (Nuclear Department, Faculty of Engineering, Alexandria University); and a $\mathrm{PhD}$ in June 1983 (High Institute of Electronic and Optics, Paul Sabatier University, Toulouse, France). From 1970 to 1977, he was in the Egyptian marine force. He was a demonstrator until 1977, in 1977 he was teaching lectures and staff members and in 1993 he was a professor with the Department of Electronic and Electrical Communications, Faculty of Electronic Engineering, Menufiya University. In 1993, he became professor of microelectronic, VLSI design technology, communication systems, and computer networks. From 1993 until 1999, he was vice dean for education and student. In 2001, he became president of the Electrical Engineering Communication Department; and from 2001 until 2004 , he was dean of the faculty of electronic engineering. He is a member of the Menufiya periodic electronic faculty journal and since 1995 have been the director, designer, and constructor of the Menufiya University wide-area network (WAN) (21-LANs). He is the developer of the Menufiya University libraries and FRCU universities libraries, His current research interests are electron and scan microscopy; transmission and backscattering of electrons and ion beams into amorphous or polycrystalline targets; optical fibers; VLSI design, nanotechnology, lithography; digital, optical, and multimedia communications; digital Images; multimedia and database communications; computer security (crypto-analyses); telemetry microcomputer applications in satellites; OBC (on Board computer Design) and satellite communications, IT, Computer Network.

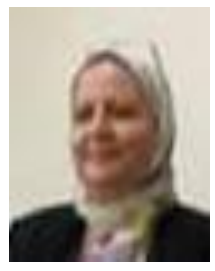

Hala Mohamed abd Elkader was born in Egypt. She received his B.sc. in electronics and Communication Engineering with honor degree in 1978, M.Sc in 1983, and Ph.D. in 1991 in Electronics all from Shoubra faculty of Engineering Zagazig University. She published many of publications as afollows, Performance Analysis of LDPC-IDMAUWB Signals in Non-Gaussian Noisy Channel(International Journal of Scientific \& Engineering Research, Volume 4, Issue 6, June 2013), Telemetry over Wireless Communication System (Engineering Research Journal, Shoubra Faculty of Engineering, Number 18, January 2013), and Fuzzy Logic Control of an Autonomous Mobile Robot (Volume 8, Number 3, September 2011 issue of the Internatonal Journal of Advanced Robotc Systems) She is currently a Prof. of Signal Processing and digital design at Shoubra Faculty of Engineering Benha University. His research includes Mobile Robot, Analog Matched Filter, Circuit, Wireless Networks, and Data Acquisition System. 